23 Thelle DS, Forde $\mathrm{OH}$. The cardiovascular study in Finnmark county: coronary risk factors and the occurrence of myocardial infarction in first degree relatives and in subjects of different ethnic origin. Am $\mathcal{f}$ Epidemio 1979;110:708-15

24 Rissanen A. Familial occurrence of coronary heart disease: effect of age at diagnosis. Am f Cardiol 1979;44:60-6.

25 Rissanen A, Nikkala E. Identification of the high risk groups in familia coronary heart disease. Atherosclerosis 1984;53:37-46.

26 Hunt SC, Williams RR, Barlow GK. A comparison of positive family history definitions for defining risk of future disease. 7 Clin Epidemiol 1986;39: $809-21$.

27 Heller R, Kelson MC. Family history in low risk men with coronary heart disease. $\mathcal{F}$ Epidemiol Community Health 1983;37:29-3
28 Phillips AN, Shaper AG, Pocock SJ, Walker M. Parental death and the risk of heart attack. Eur Heart f 1988;9:243-51.

29 Myers R, Kiely D, Cupples A, Kannel W. Parental history is an independent risk factor for coronary artery disease: the Framingham study. Am Heart $\mathcal{f}$ 1990;120:963-9.

30 Patterson CC, McCrum EE, Matthewson Z, Evans A. Validation of two methods of long term follow up. Ulster Med $f$ 1990;59:177-82.

31 Mertens TE. Estimating the effects of misclassification. Lancet 1993;342: 418-21.

32 Cicchetti DV, Feinstein AR. High agreement but low kappa. II. Resolving the paradoxes. 7 Clin Epidemiol 1990;43:551-8.

(Accepted 22 September 1993)

\title{
Further follow up of mortality and incidence of cancer in men from the United Kingdom who participated in the United Kingdom's atmospheric nuclear weapon tests and experimental programmes
}

\author{
S C Darby, G M Kendall, T P Fell, R Doll, A A Goodill, A J Conquest, D A Jackson, R G E Haylock
}

Abstract

Objectives-To study the long term effects of participation in the United Kingdom's atmospheric nuclear weapon tests and experimental programmes and to test hypotheses generated by an earlier report, including the possibility that participation in tests caused small hazards of leukaemia and multiple myeloma.

Design-Follow up study of mortality and cancer incidence.

Subjects-21358 servicemen and civilians from the United Kingdom who participated in the tests and a control group of 22333 non-participants.

Main outcome measures-Numbers of deaths; standardised mortality ratios; relative risks of mortality from all causes and 27 types of cancer.

Results-During seven further years of follow up the numbers of deaths observed in participants were fewer than expected from national rates for all causes, all neoplasms, leukaemia, and multiple myeloma (standardised mortality ratios $0.86,0.85$, 0.57 , and 0.46 ); death rates were lower than in controls (relative risks $0.99,0.96,0.57$, and 0.57 ; $90 \%$ confidence intervals all included $1 \cdot 00$ ). In the period more than 10 years after the initial participation in tests the relative risk of death in participants compared with controls was near unity for all causes (relative risk $0.99(0.95$ to 1.04$))$ and all neoplasms $(0.95(0.87$ to 1.04$))$; it was raised for bladder cancer $(2.69(1.42$ to $5 \cdot 20))$ and reduced for cancers of the mouth, tongue, and pharynx $(0.45$ $(0.22$ to 0.93$))$ and for lung cancer $(0.85(0.73$ to $0.99)$ ). For leukaemia mortality was equal to that expected from national rates but greater than in controls for both the whole follow up period $(1.75$ $(1.01$ to 3.06$))$ and the period $2-25$ years after the tests $(3.38(1 \cdot 45$ to $8 \cdot 25))$.

Conclusion-Participation in nuclear weapon tests had no detectable effect on expectation of life or on subsequent risk of developing cancer or other fatal diseases. The excess of leukaemia in participants compared with controls seems to be principally due to a chance deficit in the controls, but the possibility that participation in the tests may have caused a small risk of leukaemia in the early years afterwards cannot be ruled out.

Harkness Laboratory,

Radcliffe Infirmary, Oxford OX2 6HE

$\mathrm{R}$ Doll, honorary consultant

Correspondence to: Dr Darby.

\section{Introduction}

A previous study of the health of men from the United Kingdom who took part in the United Kingdom's programme of atmospheric nuclear weapon tests in Australia and the Pacific Ocean during the 1950s and
1960 s showed that the total mortality and the mortality from all neoplasms combined were both almost identical in test participants and in a matched control group. ${ }^{12}$ The mortality from leukaemia and from multiple myeloma was, however, substantially higher in the test participants than in controls (though not much greater than would be expected from comparison with national data), while the mortality from the two diseases most closely related to smoking was significantly lower in the test participants than in the controls. Three hypotheses were, therefore, suggested which could be tested only by further observationsnamely, that $(a)$ test participation caused small hazards of leukaemia (excluding chronic lymphatic leukaemia) and multiple myeloma; $(b)$ test participation did not cause a detectable hazard of any other cancer or of any other disease that has an appreciable death rate; and (c) that participants smoked less than other similarly employed men. The men have now been followed up for a further seven years to see whether these hypotheses could be confirmed and to examine the long term effects of test participation. The present report presents a summary of the findings. Full details are given elsewhere. ${ }^{3}$

\section{Subjects and methods}

STUDY POPULATION

The testing programme took place at the Monte Bello Islands, Emu Field, and Maralinga Range in Australia and at Malden and Christmas Islands in the Pacific Ocean. Ministry of Defence records dating from the time of the tests were searched to identify serviemen from the United Kingdom and employees of the Atomic Weapons Establishment and the Atomic Energy Research Establishment or their preceding organisations who visited one of these locations for the tests or sampled radioactive clouds. A total of 21358 participants were identified: $6304(29 \%)$ in the Royal Navy, $5794(27 \%)$ in the army, $8444(40 \%)$ in the Royal Air Force, and $816(4 \%)$ in the civilian workforce. The men are those that were studied previously, plus a few additional participants found in archival material but excluding 1503 men with no more likelihood than members of the general public of having been exposed to radiation from the tests (usually because they had left the test locations before the first detonation).

A control group of 22.333 men who had not parof Defence archives. Controls for servicemen chosen from other servicemen who had served in tropical or subtropical areas at the time of the tests. Controls for the men in the Royal Navy and for officers 
in the army and the Royal Air Force were chosen from contemporary lists of men serving in appropriate ships or units; for airmen and soldiers no contemporary lists were available and so an individually matched control was selected for each man directly from neighbouring service records in the service records offices. ${ }^{2}$ Individually matched controls for civilians were selected from other employees of the Atomic Weapons Establishment at the time of the tests. ${ }^{2}$ The distributions of test participants and controls by service, rank, year of birth, year of enlistment or employment, and year of discharge or termination of employment were closely similar.

In our previous report lists of names of test participants were also requested from organisations that had compiled lists independently of sources in the Ministry of Defence's archival material; these participants were studied separately. In the present study names of further "independent respondents" were sought from these organisations; for all those who had not been included in the main study information was requested from the Ministry of Defence to establish whether they had, in fact, participated. On the basis of this information it was estimated that $85 \%$ of all participants had been included in the main study.

\section{RADIATION EXPOSURE}

Information on film badges issued at the tests was made available by the Ministry of Defence for 5686 men, 2264 of whom had recorded doses greater than zero. The total collective $\gamma$ dose recorded was about 17 man Sv.

\section{FOLLOW UP}

The men were followed up to 1 January 1991 using information from the NHS central registers, the Department of Social Security, and the health departments in Northern Ireland, the Isle of Man, Jersey, and Guernsey. Eight per cent of participants $(1750 / 21358)$ and $7 \%$ of controls $(1613 / 22333)$ had emigrated, $13 \%$ of both groups had died (2755 participants, 2949 controls), $79 \%$ of both groups were alive and living in the United Kingdom $(16797,17721)$, and less than $0.5 \%$ of both groups were lost to follow up $(56,50)$. Causes of death were coded according to the ninth revision of the International Classification of Diseases (ICD-9). ${ }^{4}$ To analyse the incidence of cancer, data on mortality were augmented by adding incident cases recorded in the NHS central registers or mentioned as a contributory cause on death certificates.

\section{METHOD OF ANALYSIS}

Participants were entered into the study when they first participated in a test. Controls, with the exception of soldiers and civilians, were entered at the time of the overseas visit which led to their inclusion in the control group; soldier controls were entered into the study on the date of termination of their reserve liability, and civilian controls were entered into the study on the date that the participant with whom they were matched took part in his first test. Men were removed from the study on the date of their death, emigration, or 85th birthday or on 31 December 1990, whichever was the earliest. For the analyses of cancer incidence men were also removed on the date of cancer registration when appropriate. Standardised mortality ratios were calculated from national mortality statistics in five year age groups for single calendar years. Two sided tests were used for calculating the significance of standardised mortality ratios, and $95 \%$ confidence intervals are shown in the usual way.

To compare mortality in participants and controls the data were stratified into five year age and calendar year groups by service and by rank. Relative risks were estimated by maximum likelihood. We were specifically interested in testing the hypothesis that mortality and the incidence of cancer were greater among participants than controls so, as in the previous report, ${ }^{1}$ one sided tests (in the direction of the observed difference) were used to calculate the significance of relative risks with corresponding $90 \%$ confidence intervals.

\section{Results}

STUDY OF HYPOTHESES GENERATED BY PREVIOUS REPORT

Table I shows the results for all conditions for which significant differences in mortality or cancer incidence between participants and controls were reported previously $^{12}$ as well as for broad groups of causes. Results up to 1983 and for 1984-90 are shown separately.

For leukaemia and multiple myeloma standardised mortality ratios in participants up to 1983 were slightly above 1 and relative risks for participants compared with controls significantly greater than 1 , but in 1984-90 standardised mortality ratios and relative risks for participants were all less than unity. For prostate and kidney cancers standardised mortality ratios in participants up to 1983 were initially below 1 and relative risks significantly less than 1 , but both results were subsequently greater than 1 . For bronchitis, emphysema, and chronic obstructive lung disease standardised mortality ratios for both groups were initially below 1 and the relative risk for participants was significantly less than 1 ; in 1984-90 standardised mortality ratios remained low but the relative risk for participants was significantly raised. For other injury

TABLE I-Numbers of observed deaths and standardised mortality ratios among test participants and controls, with relative risks of mortality among test participants compared with controls for selected causes of death by calendar period

\begin{tabular}{|c|c|c|c|c|c|c|c|c|c|c|}
\hline \multirow[b]{3}{*}{ Cause of death } & \multicolumn{5}{|c|}{ Up to 31 Dec $1983 \dagger$} & \multicolumn{5}{|c|}{1 Jan 1984-31 Dec 1990} \\
\hline & \multicolumn{2}{|c|}{$\begin{array}{c}\text { Test } \\
\text { participants }\end{array}$} & \multicolumn{2}{|c|}{ Controls } & \multirow{2}{*}{$\begin{array}{c}\text { Mortality in test } \\
\text { participants relative to } \\
\text { controls (relative risk } \\
(90 \% \text { confidence } \\
\text { interval) })\end{array}$} & \multicolumn{2}{|c|}{$\begin{array}{c}\text { Test } \\
\text { participants }\end{array}$} & \multicolumn{2}{|c|}{ Controls } & \multirow{2}{*}{$\begin{array}{c}\text { Mortality in test } \\
\text { participants relative to } \\
\text { controls (relative risk } \\
(90 \% \text { confidence } \\
\text { interval }))\end{array}$} \\
\hline & $\begin{array}{c}\text { Observed } \\
\text { No of deaths }\end{array}$ & $\begin{array}{l}\text { Standardised } \\
\text { mortality ratio }\end{array}$ & $\begin{array}{c}\text { Observed } \\
\text { No of deaths }\end{array}$ & $\begin{array}{c}\text { Standardised } \\
\text { mortality ratio }\end{array}$ & & $\begin{array}{c}\text { Observed } \\
\text { No of deaths }\end{array}$ & $\begin{array}{c}\text { Standardised } \\
\text { mortality ratio }\end{array}$ & $\begin{array}{c}\text { Observed } \\
\text { No of deaths }\end{array}$ & $\begin{array}{c}\text { Standardised } \\
\text { mortality ratio }\end{array}$ & \\
\hline \multicolumn{11}{|c|}{ Causes with significant difference berween test participants and controls in previous analysis' ${ }^{2}$} \\
\hline Leukaemia & 23 & 1.25 & 6 & 0.32 & $3.93(1.71 \text { to } 9.49)^{\star \star}$ & 6 & 0.57 & 11 & 0.98 & $0.57(0.22$ to 1.46$)$ \\
\hline Multiple myeloma & 6 & $1 \cdot 17$ & 0 & 0.00 & $\infty(1.96 \text { to } \infty)^{\star \star \star}$ & 3 & 0.46 & 6 & 0.86 & $0.57(0.13$ to 2.17$)$ \\
\hline Cancer of: & & & & & & & & & & \\
\hline Lung & 120 & 0.68 & 158 & 0.82 & $0.86(0.70$ to 1.06$)$ & 122 & 0.79 & 145 & 0.88 & $0.89(0.72$ to $1 \cdot 10)$ \\
\hline Prostate & 9 & 0.89 & 22 & 1.86 & $0.44(0.21 \text { to } 0.91)^{\star}$ & 25 & 1.08 & 19 & 0.76 & $1.55(0.90$ to 2.70$)$ \\
\hline Kidney & 5 & 0.48 & 21 & 1.86 & $0.25(0.10 \text { to } 0.62)^{\star \star \star \star}$ & 16 & 1.44 & 15 & $1 \cdot 27$ & $1.08(0.56$ to 2.07$)$ \\
\hline Bronchitis, emphysema, and chronic obstructive lung disease & 20 & 0.31 & 38 & 0.52 & $0.56(0.34 \text { to } 0.92)^{\star}$ & 48 & 0.77 & 33 & 0.49 & $1.57(1.05 \text { to } 2.34)^{\star}$ \\
\hline Other injury and poisoning $\ddagger$ & 101 & 1.28 & 75 & 0.96 & $1.38(1.05 \text { to } 1.81)^{\star}$ & 30 & 1.31 & 32 & 1.31 & $1.00(0.64$ to 1.57$)$ \\
\hline \multicolumn{11}{|c|}{ Other selected causes of death } \\
\hline Neoplasms: & & & & & & & & & & \\
\hline & 392 & 0.81 & 439 & 0.83 & $0.96(0.86$ to 1.08$)$ & 370 & 0.85 & 411 & 0.88 & $0.96(0.85$ to 1.08$)$ \\
\hline All other than those above & 229 & 0.87 & 232 & 0.82 & $1.04(0.89$ to 1.22$)$ & 198 & 0.85 & 215 & 0.87 & $0.98(0.83$ to 1.16$)$ \\
\hline All non-neoplastic diseases & 810 & 0.70 & 869 & 0.69 & $1.01(0.93$ to 1.10$)$ & 754 & 0.85 & 793 & 0.83 & $1.02(0.94$ to 1.11$)$ \\
\hline Accidents and violence & 315 & 1.27 & 299 & 1.24 & $1.06(0.92$ to 1.22$)$ & 57 & 0.98 & 60 & 0.98 & $1.03(0.75$ to 1.42$)$ \\
\hline Unknown cause & 39 & & 41 & & & 16 & & 27 & & \\
\hline All causes & 1556 & 0.82 & 1648 & 0.81 & $1.01(0.95$ to 1.07$)$ & 1197 & 0.86 & 1291 & 0.87 & $0.99(0.93$ to 1.06$)$ \\
\hline
\end{tabular}

$p \leqslant 0.05, \star \star p \leqslant 0.01, \star \star \star p \leqslant 0.001$ (one sided test).

†Previous follow up date. Numbers differ slightly from those given previously ${ }^{2}$ owing to slightly different definition of a test participant used and to inclusion of some men who were untraced at time of previous report.

tOther than motor vehicle traffic accidents, drowning and water transport accidents, air and space transport accidents, or suicide. 


\begin{tabular}{|c|c|c|c|c|c|c|c|c|}
\hline \multirow[b]{3}{*}{ Cause of death } & \multicolumn{8}{|c|}{ Time since initial test participation (years) } \\
\hline & \multicolumn{2}{|c|}{$<10$} & \multicolumn{2}{|c|}{$10-19$} & \multicolumn{2}{|c|}{$20-29$} & \multicolumn{2}{|c|}{$\geqslant 30$} \\
\hline & $\begin{array}{l}\text { Observed } \\
\text { No of deaths }\end{array}$ & $\begin{array}{l}\text { Standardised } \\
\text { mortality ratio }\end{array}$ & $\begin{array}{l}\text { Observed } \\
\text { No of deaths }\end{array}$ & $\begin{array}{l}\text { Standardised } \\
\text { mortality ratio }\end{array}$ & $\begin{array}{l}\text { Observed } \\
\text { No of deaths }\end{array}$ & $\begin{array}{l}\text { Standardised } \\
\text { mortality ratio }\end{array}$ & $\begin{array}{c}\text { Observed } \\
\text { No of deaths }\end{array}$ & $\begin{array}{c}\text { Standardised } \\
\text { mortality ratio }\end{array}$ \\
\hline Neoplasms & 53 & $0 \cdot 72$ & 159 & 0.85 & 350 & $0 \cdot 81$ & 200 & 0.87 \\
\hline Other diseases & 97 & 0.54 & 319 & $0 \cdot 70$ & 755 & 0.79 & 393 & 0.86 \\
\hline Accidents and violence & 147 & $1 \cdot 34$ & 94 & 1.09 & 105 & $1 \cdot 24$ & 26 & 1.08 \\
\hline Unknown & 6 & & 18 & & 24 & & 7 & \\
\hline All causes & 303 & 0.84 & 590 & 0.81 & 1234 & 0.83 & 626 & 0.88 \\
\hline
\end{tabular}

and poisoning the standardised mortality ratio in participants and the relative risk were initially above 1 ; standardised mortality ratios were subsequently above 1 in both groups and the relative risk was 1.00 precisely. Finally, for lung cancer, for which the relative risk had previously been significantly low for cancer incidence and for mortality when the first 10 years of observation were omitted, the relative risk was not significantly different from unity in either time period.

For the broad groups of causes the relative risks in participants versus controls were similar in both periods, having values of 0.96 and 0.96 respectively for all neoplasms and 1.01 and 0.99 for all causes. Similar relative risks were obtained for the cancers shown in table I when the analysis was repeated using cancer incidence.

LONG TERM EFFECT OF TEST PARTICIPATION ON HEALTH

Mortality in test participants for different times since the initial participation is shown in table II. For non-neoplastic diseases the effect of selecting healthy men for participation was pronounced in the first 10 years (standardised mortality ratio 0.54 ) and then decreased progressively; for neoplasms the initial effect of selection was weaker (standardised mortality ratio 0.72 ) and there was little trend after 10 years, although standardised mortality ratios remained low for the entire study. For accidents and violence the standardised mortality ratio was initially high and then diminished as the men changed from service to civilian life.

In many studies of the effects of radiation increases in risk are clearest more than 10 years after exposure for cancers other than leukaemia. ${ }^{5}$ Therefore to avoid the time when the effect of selecting healthy men is greatest, and to maximise the chance of detecting a hazard that was not apparent in our earlier report, we concentrated on the period more than 10 years after initial participation. During this time the standardised mortality ratios from all causes, all neoplasms, and all other diseases were below unity in participants, but the standardised mortality ratio of accidents and violence was above unity (table III). The social class structure of the participants differed from that of the general population, with more officers and more employees in social class I. When standardised mortality ratios were adjusted for social class by using national death rates

TABLE III-Observed numbers of deaths and standardised mortality ratios uncorrected and corrected for social class among test participants more than 10 years after initial participation in test, with relative risks of mortality in test participants compared with controls over corresponding period by broad cause of death

\begin{tabular}{|c|c|c|c|c|}
\hline \multirow[b]{3}{*}{ Cause of death } & \multicolumn{3}{|c|}{ Test participants } & \multirow{3}{*}{$\begin{array}{c}\text { Mortality rate in test } \\
\text { participants relative to controls } \\
\text { (relative risk } \\
(90 \% \text { confidence interval)) }\end{array}$} \\
\hline & \multirow[b]{2}{*}{ Observed No of deaths } & \multicolumn{2}{|c|}{ Standardised mortality ratio } & \\
\hline & & Unadjusted & $\begin{array}{l}\text { Adjusted for } \\
\text { social class }\end{array}$ & \\
\hline Neoplasms & 709 & 0.84 & 0.87 & $0.95(0.87$ to 1.04$)$ \\
\hline Other diseases & 1467 & 0.78 & 0.85 & $1.01(0.95$ to 1.07$)$ \\
\hline Accidents and violence & 225 & $1 \cdot 15$ & 1.31 & $1.11(0.94$ to 1.31$)$ \\
\hline Unknown & 49 & & & \\
\hline All causes & 2450 & 0.84 & 0.90 & $0.99(0.95$ to 1.04$)$ \\
\hline
\end{tabular}

specific for social class (rates for men in social class I for officers and employees in social class I and rates for men in social class III (manual and non-manual combined) for other servicemen and employees) they were slightly higher but, with the exception of accidents and violence, were still less than unity. For these broad groups of causes little difference was observed between the participants and controls, with all relative risks close to and not significantly different from unity.

Table IV gives results for the period more than 10 years after initial test participation for 26 cancers other than leukaemia. For leukaemia, in which radiation related increases usually reach a maximum within five years of exposure, ${ }^{5}$ data are given for the entire follow up period and for 2-25 years after the initial participation in tests. The relative risk for participants compared with controls was significantly greater than unity only for bladder cancer $(2.69$ ( $90 \%$ confidence interval 1.42 to 5.20 ), and leukaemia (whole follow up: 1.75 (1.01 to 3.06$)$; $2-25$ years: 3.38 $(1.45$ to $8 \cdot 25)$ ). For both diseases the standardised mortality ratio for participants was close to unity, while that for controls was very low. The relative risk for participants compared with controls was significantly less than unity only for cancers of the mouth, tongue, and pharynx $(0.45(0.22$ to 0.93$))$ and for lung cancer $(0.85(0.73$ to 0.99$))$. For the remaining cancers death rates in participants and controls were similar $(p>0.10$ in all cases apart from liver cancer, for which $p=0 \cdot 07$ ). When the analysis was repeated for cancer incidence the relative risk for all neoplasms was $0.97(0.91$ to 1.04)). For the individual cancer types relative risks were similar to those for mortality, except that the relative risk for liver cancer was significantly raised $(2.89(1.11$ to 7.94$))$; the relative risk for bladder cancer was lower, although still significantly raised ( 1.45 ( 1.03 to 2.03$))$; the relative risk for non-melanoma skin cancer was significantly low $(0.77(0.63$ to 0.95$))$; and the relative risk for lung cancer and cancers of the mouth, tongue, and pharynx were no longer significantly different from unity. When chronic lymphatic leukaemia was excluded the relative risk for the remaining leukaemia subtypes was $1.55(0.92$ to 2.62 ) for the whole follow up and 3.98 (1.73 to 9.62$)$ for the 2-25 year period. When mortality was examined for 10 groups of diseases other than neoplasms no significant differences were observed between participants and controls. ${ }^{3}$

\section{MORTALITY AND CANCER INCIDENCE BY TYPE AND} DEGREE OF EXPOSURE

Among 2264 men with known doses of $\gamma$ radiation standardised mortality ratios were low for leukaemia (whole follow up: $0.69(95 \%$ confidence interval 0.08 to $2.48)$; 2 -25 years: $0.66(0.02$ to 3.66$))$ and for other neoplasms ( $>10$ years: $0.66(0.51$ to 0.84$))$; they were lower than those for 3422 men who were monitored but had zero recorded doses (leukaemia whole follow up: $0.79(0.21$ to 2.02$)$; $2-25$ years: $0.80(0.10$ to $2 \cdot 88)$; other neoplasms $>10$ years: $0.82(0.69$ to 0.97$))$. Incidence also tended to decrease slightly but not 
TABLE $\mathrm{V}-O b s e r v e d$ numbers of deaths and standardised mortality ratios among test participants and controls, with relative risks of mortality in test participants compared with controls for leukaemia and 26 other specific types of cancer. For leukaemia the whole follow up period and the period 2-25 years after initial participation in the tests are considered, and for other specific cancers the period more than 10 years after first participation is considered

\begin{tabular}{|c|c|c|c|c|c|}
\hline \multirow[b]{2}{*}{ Type of cancer (ICD-9 code) } & \multicolumn{2}{|c|}{ Test participants } & \multicolumn{2}{|c|}{ Controls } & \multirow{2}{*}{$\begin{array}{l}\text { Mortality in test participants } \\
\text { relative to controls (relative } \\
\text { risk ( } 90 \% \text { confidence interval)) }\end{array}$} \\
\hline & Observed No of deaths & Standardised mortality ratio & Observed No of deaths & Standardised mortality ratio & \\
\hline Mouth, tongue, pharynx $(141,143-149)$ & 10 & $0 \cdot 71$ & 22 & $1 \cdot 49$ & $0.45(0.22 \text { to } 0.93)^{\star}$ \\
\hline Oesophagus (150) & 39 & $1 \cdot 20$ & 35 & 1.02 & $1.19(0.79$ to 1.80$)$ \\
\hline Stomach (151) & 48 & $0 \cdot 70$ & 55 & 0.75 & $0.94(0.66$ to 1.32$)$ \\
\hline \multicolumn{6}{|l|}{ Large intestine and rectum $(153,154$ excluding } \\
\hline $154.3,159.0)$ & 82 & $0 \cdot 88$ & 82 & 0.83 & $1.04(0.79$ to 1.36$)$ \\
\hline Liver (155) & 12 & 1.33 & 5 & 0.53 & $2.46(0.92$ to 6.92$)$ \\
\hline Gall bladder (156) & 1 & $0 \cdot 24$ & 4 & 0.89 & $0.24(0.01$ to 1.79$)$ \\
\hline Pancreas (157) & 38 & $1 \cdot 01$ & 35 & 0.87 & $1.11(0.74$ to 1.68$)$ \\
\hline Larynx (161) & 8 & 0.95 & 14 & 1.56 & $0.60(0.26$ to 1.34$)$ \\
\hline Lung $(162,163)$ & 228 & 0.74 & 285 & 0.86 & $0.85(0.73 \text { to } 0.99)^{\star}$ \\
\hline Bone $(170)$ & 1 & 0.42 & 1 & 0.41 & $1.07(0.04$ to 29.19$)$ \\
\hline Connective and soft tissue (171) & 2 & 0.52 & 3 & 0.76 & $0.74(0.11$ to 4.37$)$ \\
\hline Malignant melanoma (172) & 15 & 1.62 & 13 & 1.38 & $1.22(0.61$ to 2.44$)$ \\
\hline Other skin cancer (173) & 0 & 0.00 & 0 & 0.00 & - \\
\hline Prostate (185) & 34 & 1.04 & 41 & $1 \cdot 13$ & $0.93(0.62$ to 1.41$)$ \\
\hline Testis (186) & 4 & 0.83 & 3 & 0.68 & $1.23(0.27$ to 5.91$)$ \\
\hline Bladder $(188,189.3-189.9)$ & 27 & 1.04 & 11 & 0.39 & $2.69(1.42 \text { to } 5.20)^{\star \star}$ \\
\hline Kidney $(189.0-189.2)$ & 21 & 1.04 & 32 & 1.50 & $0.68(0.41$ to 1.12$)$ \\
\hline \multirow{2}{*}{\multicolumn{6}{|c|}{ Tumours of central nervous system $(191,192$, }} \\
\hline & 39 & 1.01 & 38 & 0.96 & $1.04(0.69$ to 1.56$)$ \\
\hline Thyroid (193) & 0 & 0.00 & 1 & 0.60 & $0.00(0.00$ to 13.14$)$ \\
\hline Adrenals $\dagger(194.0)$ & 1 & 1.57 & 2 & $3 \cdot 10$ & $0.58(0.03$ to 6.31$)$ \\
\hline Hodgkin's disease (201) & 3 & 0.37 & 8 & 1.02 & $0.41(0.10$ to 1.41$)$ \\
\hline \multicolumn{6}{|l|}{ Non-Hodgkin lymphoma $(200,202.0-202.3$, } \\
\hline $202.5-202.9)$ & 19 & 0.85 & 17 & 0.73 & $1.02(0.55$ to 1.89$)$ \\
\hline \multicolumn{6}{|l|}{ Multiple myeloma (203, excluding 203.1, } \\
\hline 238.6) & 8 & 0.72 & 6 & 0.51 & $1.51(0.55$ to 4.26$)$ \\
\hline \multicolumn{6}{|l|}{ Leukaemia (whole period) } \\
\hline$(202.4,203.1,204-208)$ & 29 & 1.00 & 17 & 0.56 & $1.75(1.01 \text { to } 3.06)^{\star}$ \\
\hline Leukaemia $(2-25$ years $)$ & 20 & 1.23 & 6 & 0.34 & $3.38(1.45 \text { to } 8.25)^{\star \star}$ \\
\hline Polycythaemia verał (238.4) & 1 & $1 \cdot 30$ & 1 & $1 \cdot 22$ & $1.12(0.04$ to 30.71$)$ \\
\hline \multicolumn{6}{|l|}{ Other specified neoplasms (140-239 excluding } \\
\hline \multirow{2}{*}{\multicolumn{6}{|c|}{ Unspecified neoplasms (196-199, 239 excluding }} \\
\hline & & & & & \\
\hline $239 \cdot 6)$ & 31 & 0.69 & 42 & 0.88 & $0.83(0.54$ to 1.26$)$ \\
\hline All neoplasms (140-239) & 709 & 0.84 & 787 & 0.87 & $0.95(0.87$ to 1.04$)$ \\
\hline
\end{tabular}

${ }^{\star} \mathrm{p} \leqslant 0.05 ;{ }^{\star \star} \mathrm{p} \leqslant 0.01$ (one sided test)

tIncluded only from 1958 in the comparison with national rates; no participant or control died of adrenal cancer before this.

IIncluded only from 1968 in the comparison with national rates; no participant or control died of polycythaemia vera before this.

significantly (one sided test, $\mathrm{p}>0 \cdot 10$ ) with increasing recorded dose in each of these three categories. ${ }^{3}$

Because mortality from leukaemia was lower in men who were monitored than in test participants as a whole, mortality from leukaemia and other neoplasms was further investigated by type of test participation. For leukaemia standardised mortality ratios were below unity for participants present at a major operation, participants in groups identified by the Ministry of Defence as liable to exposure to radiation, and participants employed by the Atomic Weapons Establishment or directly involved in the minor trials at Maralinga (table V). Only among participants who were not in these three groups were the standardised mortality ratios for leukaemia raised (whole follow up: $1.41(0.65$ to $2 \cdot 68) ; 2-25$ years: $2 \cdot 22(1.01$ to $4 \cdot 21))$. For other neoplasms standardised mortality ratios were below unity in all four groups. Further analyses by individual operation did not show any significant increases and the men developing leukaemia were not concentrated in any identified job. ${ }^{3}$
MORTALITY OF INDEPENDENT RESPONDENTS

In the previous report mortality was examined in independent respondents who had been identified before 31 March 1986 and who were not in the main study. Table VI shows the mortality in the same group separately for the period up to 31 March 1986 and for 1 April 1986 to 31 December 1990. In the earlier period mortality from all causes, all neoplasms, and leukaemia were all substantially raised (standardised mortality ratios for all causes 2.05 ( 1.61 to 2.57 ; all neoplasms 5.18 ( 3.83 to 6.85$)$; and leukaemia $10.66(2.87$ to 26.95)). This was to be expected as independent respondents were mainly the men who had contacted the organisation that had given us the man's name or men whose relatives had contacted the organisation. They thus form a highly selected group, and their mortality up to the end of the period of enrolment was unlikely to be representative of participants as a whole. In the period after enrolment ceased, however, mortality from all causes was close to that expected (standardised mortality ratio $1.17(0.69$ to 1.85$)$ );

TABLE V-Observed numbers of deaths and standardised mortality ratios for test participants by nature of test participation for selected types of cancer. For leukaemia the whole follow up period and the period 2-25 years after first test participation are considered. For other neoplasms the period more than 10 years after first participation is considered

\begin{tabular}{|c|c|c|c|c|c|c|c|c|}
\hline \multirow[b]{2}{*}{ Type of cancer } & \multicolumn{2}{|c|}{$\begin{array}{l}\text { Present at a major operation } \\
(n=15633)^{\star}\end{array}$} & \multicolumn{2}{|c|}{$\begin{array}{l}\text { In groups identified by } \mathrm{MoD} \text { as } \\
\text { liable to exposure to radiation } \\
(\mathrm{n}=5118) \dagger\end{array}$} & \multicolumn{2}{|c|}{$\begin{array}{l}\text { Employed by AWE or directly } \\
\text { involved in the minor trials at Maralinga } \\
(\mathrm{n}=1041) \ddagger\end{array}$} & \multicolumn{2}{|r|}{$\begin{array}{c}\text { Other } \\
(\mathrm{n}=5165) \|\end{array}$} \\
\hline & $\begin{array}{l}\text { Observed } \\
\text { No of deaths }\end{array}$ & $\begin{array}{l}\text { Standardised mortality } \\
\text { ratio ( } 95 \% \text { confidence } \\
\text { interval) }\end{array}$ & $\begin{array}{l}\text { Observed } \\
\text { No of deaths }\end{array}$ & $\begin{array}{l}\text { Standardised mortality } \\
\text { ratio ( } 95 \% \text { confidence } \\
\text { interval) }\end{array}$ & $\begin{array}{c}\text { Observed } \\
\text { No of deaths }\end{array}$ & $\begin{array}{l}\text { Standardised mortality } \\
\text { ratio ( } 95 \% \text { confidence } \\
\text { interval) }\end{array}$ & $\begin{array}{l}\text { Observed } \\
\text { No of deaths }\end{array}$ & $\begin{array}{l}\text { Standardised mortality } \\
\text { ratio ( } 95 \% \text { confidence } \\
\text { interval) }\end{array}$ \\
\hline $\begin{array}{l}\text { Leukaemia (whole follow up period) } \\
\text { Leukaemia ( } 2-25 \text { years) } \\
\text { Other neoplasms ( } \geqslant 10 \text { years) }\end{array}$ & $\begin{array}{r}19 \\
10 \\
539\end{array}$ & $\begin{array}{l}0.87(0.52 \text { to } 1.36) \\
0.85(0.41 \text { to } 1.57) \\
0.86(0.79 \text { to } 0.94)\end{array}$ & $\begin{array}{r}7 \\
3 \\
209\end{array}$ & $\begin{array}{l}0.83(0.33 \text { to } 1.71) \\
0.70(0.15 \text { to } 2.06) \\
0.77(0.67 \text { to } 0.88)\end{array}$ & $\begin{array}{r}2 \\
1 \\
49\end{array}$ & $\begin{array}{l}0.96(0.12 \text { to } 3.47) \\
0.89(0.02 \text { to } 4.93) \\
0.66(0.49 \text { to } 0.87)\end{array}$ & $\begin{array}{r}9 \\
9 \\
129\end{array}$ & $\begin{array}{l}1.41(0.65 \text { to } 2.68) \\
2.22(1.01 \text { to } 4.21) \\
0.74(0.62 \text { to } 0.88)\end{array}$ \\
\hline
\end{tabular}

MoD=Ministry of Defence. AWE=Atomic Weapons Establishment.

^One or more of Operations Hurricane, Totem, Mosaic, Buffalo, Antler, Grapple, Grapple X, Grapple Y, Grapple Z, or Brigadoon.

$\dagger$ Members of the Buffalo Indoctrinee Force, aircrews who sampled radioactive clouds, airman on active handling flights who decontaminated aircraft, HMS Diana's crew at Operation Mosaic, and the Target Response Group at Buffalo.

$¥$ Those in whom undocumented inhalation or ingestion of radionuclides, if any, is most likely to have occurred.

|Largely those who visited test areas between or after the tests. 
TABLE VI-Observed numbers of deaths and standardised mortality ratios among independent respondents known at the time of the previous analysis and found not to be in the main study for selected causes of death by calendar period*

\begin{tabular}{|c|c|c|c|c|}
\hline \multirow[b]{2}{*}{ Cause of death } & \multicolumn{2}{|c|}{ Up to $31 \mathrm{Mar} 1986$} & \multicolumn{2}{|c|}{1 April 1986-31 Dec 1990} \\
\hline & $\begin{array}{l}\text { Observed } \\
\text { No of deaths }\end{array}$ & $\begin{array}{l}\text { Standardised mortality ratio } \\
(95 \% \text { confidence interval })\end{array}$ & $\begin{array}{l}\text { Observed } \\
\text { No of deaths }\end{array}$ & $\begin{array}{l}\text { Standardised mortality ratio } \\
\text { ( } 95 \% \text { confidence interval) }\end{array}$ \\
\hline All neoplasms & 49 & $5.18(3.83 \text { to } 6.85)^{\star \star \star}$ & 4 & $0.81(0.22$ to 2.07$)$ \\
\hline Leukaemia & 4 & $10.66(2.87 \text { to } 26.95)^{\star \star \star}$ & 0 & $0.00(0.00$ to 30.75$)$ \\
\hline Multiple myeloma & 0 & $0.00(0.00$ to 36.90$)$ & 0 & $0.00(0.00$ to 46.13$)$ \\
\hline Other neoplasms & 45 & $5.01(3.66 \text { to } 6.71)^{\star \star \star}$ & 4 & $0.84(0.23$ to 2.16$)$ \\
\hline Other diseases & 24 & $1.09(0.70$ to 1.62$)$ & 13 & $1.34(0.71$ to 2.28$)$ \\
\hline Accidents and violence & 1 & $0.20(0.00$ to 1.10$)$ & 0 & $0.00(0.00$ to 5.35$)$ \\
\hline Unknown & $i$ & - & 1 & - \\
\hline All causes & 75 & $2.05(1.61 \text { to } 2.57)^{\star \star \star}$ & 18 & $1.17(0.69$ to 1.85$)$ \\
\hline
\end{tabular}

$\star \star \star \mathrm{p} \leqslant 0.001$ (two sided test).

*Overall 414 independent respondents were included in the previous report, but two were found not to satisfy the revised definition of a test participant and so have been excluded.

mortality from all neoplasms was less than expected (standardised mortality ratio $0.81(0.22$ to $2 \cdot 07)$ ) and there were no deaths from leukaemia.

\section{Discussion}

GENERAL CONSIDERATIONS

Despite extensive efforts, the present study includes only an estimated $85 \%$ of participants. This raises the possibility of differential selection. In this analysis the period of additional follow up, providing $43 \%$ of deaths, is almost all prospective as nearly all the men were identified at the beginning of the period and their inclusion is unrelated to any subsequent diseases. In the previous report mortality among independent respondents omitted from the main study was high. During prospective follow up after enrolment ceased, however, standardised mortality ratio for all causes of death among independent respondents was close to unity and the ratio for cancer was similar to that for participants included in the study (table VI).

Harmful effects associated with the tests could be obscured by including among the participants men who were only peripherally involved. Therefore men who had no more potential for radiation exposure from the tests than the general public have been excluded from the main group, although their follow up has continued separately. ${ }^{3} \mathrm{~A}$ harmful effect of participating in the tests could also be diluted by including the years immediately after the tests, shortly after the men had been selected as fit and healthy. Therefore, with the exception of leukaemia, which has been observed in excess in irradiated populations within five years of exposure, we have eliminated the 10 years after initial test participation, although results for the entire period of follow up are available elsewhere. ${ }^{3}$

\section{LEUKAEMIA AND MULTIPLE MYELOMA}

The hypothesis that test participation might have caused small hazards of leukaemia (other than chronic lymphatic leukaemia) and multiple myeloma was based on high relative risks in participants compared with controls up to the end of 1983 (table I). The size and importance of both excesses, however, were principally due to the scarcity of cases in the control group and may have been due to chance. The additional follow up has supported this alternative hypothesis. For both diseases standardised mortality ratios in controls were close to unity for 1984-90 and greater than those in participants. For multiple myeloma the standardised mortality ratio for the period more than 10 years after initial test participation was below unity (table IV) and neither the incidence of nor the mortality from the disease is exceptionally high in participants compared with controls. The excess of multiple myeloma in participants compared with controls reported previously therefore seems likely to have been a chance finding.
Interpretation of the results for leukaemia is less straightforward. We anticipated that any risk would most likely be concentrated between two and 25 years after the initial participation. During this time the standardised mortality ratio was slightly greater than unity and the incidence of and mortality from leukaemia were both significantly greater in participants than controls (table IV). Furthermore, a report on Royal New Zealand Navy staff participating in the Grapple operations showed a significant increase in mortality from leukaemia, compared with national rates (four deaths $v 0.6$ expected, $\mathrm{p}=0.003$ ) and with a control group of Royal New Zealand Navy staff who did not attend the tests (relative risk $5.58(1.04$ to 41.6$)$ ). ${ }^{6}$

This evidence is, however, weak. Firstly, for the entire follow up period the standardised mortality ratio for leukaemia among participants was 1.00 (table IV). Secondly, continued observation has shown that the low standardised mortality ratio for the controls up to 1983 was atypical because the ratio was subsequently close to unity (table I). Thirdly, the highest standardised mortality ratio was found in men who were not present at a major operation, who were not in groups identified by the Ministry of Defence as liable to exposure to radiation, and who were not employed by the Atomic Weapons Establishment or directly involved in the minor trials at Maralinga (those in whom undocumented inhalation or ingestion, if any, is most likely to have occurred) (table V). Also risk did not increase with increasing recorded dose. ${ }^{3}$ The recorded doses were, moreover, very small and are estimated to cause a less than $50 \%$ chance of developing one fatal case in the entire cohort. ${ }^{7-9}$ Fourthly, the excess in Royal New Zealand Navy staff is difficult to attribute to the tests. According to the Ministry of Defence, the ships of the Royal New Zealand Navy were at least $40 \mathrm{~km}$ from the detonations and so would not have been irradiated directly. Both ships visited Christmas Island after the tests, but this seems unlikely to have caused any increase when little or none was seen in staff from the United Kingdom serving at Christmas Island (16 deaths observed and 14.30 expected for all participants in the Grapple series from the United Kingdom). Three of the four deaths in the Royal New Zealand Navy occurred more than 25 years after the tests, which would not be expected if they were caused by irradiation at the time of the tests.

On balance, the excess of leukaemia in participants compared with controls seems likely to be a chance finding due to an exceptionally low rate in the controls in the early period. However, the possibility that participants experienced some small risk of developing leukaemia in the first 25 years (standardised mortality ratio 1.23 ) cannot be ruled out, although, if they did there is no evident explanation for it.

\section{OTHER DISEASES}

The hypothesis that participation in tests did not cause a detectable hazard of other cancers or of other diseases with appreciable mortality is supported by the further data. For all neoplasms and all causes, mortality is again almost identical in participants and controls in the extended period (relative risks 0.96 and 0.99 respectively; table I). The standardised mortality ratios for these diseases are slightly higher in the extended period than before as the effect of selecting healthy workers diminished.

When many diseases are examined some differences will occur by chance. In table I, for example, high rates from prostate and kidney cancers in the controls and the significant differences between the participants and controls up to 1983 subsequently disappeared. We examined 27 cancer sites. As one sided tests have been used to compare the mortality of participants and controls three significant differences would occur 


\section{Clinical implications}

- A study published in 1988 which compared the mortality and incidence of cancer in men who participated in nuclear weapon tests with those in a control group suggested that the participants might have had a greater risk of leukaemia and myelomatosis but not of other diseases

- This study extended the follow up for seven years and found that mortality from all causes and from all neoplasms was similar in both groups and less than expected from national rates

- Compared with national rates the only notable excess of deaths was from accidents and violence, which occurred equally in both groups

- In the past seven years mortality from leukaemia and myelomatosis was lower in participants than in controls

- Participation in the tests had no detectable effect on expectation of life or on the incidence of cancer but the possibility of a small risk of leukaemia in the 25 years after the tests cannot be excluded

by chance on average. In fact four have occurred, including one for leukaemia. The other three are increases in bladder cancer and deficits in lung cancer and cancers of the mouth, tongue, and pharynx (mortality analyses) (table IV) and increases in cancers of liver and bladder and a deficit of non-melanoma skin cancer (incidence analyses). For bladder cancer the data are suggestive of a chance effect as the difference between participants and controls is greater for mortality (relative risk 2.69) than for incidence (relative risk 1.45 ) and the standardised mortality ratio in the controls is very low (0.39). For liver cancer the raised relative risk in the incidence analysis may also be partly due to a low rate among the controls, as suggested by the mortality analysis (standardised mortality ratio 0.53). Moreover, examination of the detailed description on the death certificates and cancer registrations showed that several of the so-called liver cancers should not have been described as such; the numbers of definite primary liver cancers in the two groups were respectively 10 and four. This difference is not significant $(p=0.09)$ and could well be due to chance. A raised risk of liver cancer was also observed in the test participants exposed to no more radiation than the general public (standardised mortality ratio $4.47){ }^{3}$ This suggests that any increase in liver cancer not due to chance was unconnected with exposure to radiation.

\section{SMOKING HABITS OF TEST PARTICIPANTS COMPARED WITH CONTROLS}

The hypothesis that test participants smoked less than controls is not supported by the additional data. In the extended follow up rates of lung cancer were similar in the two groups, and for bronchitis, emphysema, and chronic obstructive lung disease rates in the participants exceeded those in controls (table I). Previous results suggesting this hypothesis were probably chance observations, and it would be inappropriate to consider smoking related diseases separately from other diseases in examining the effect of test participation on mortality or cancer incidence.

\section{CONCLUSION}

Participation in nuclear weapon tests has not had a detectable effect on participants' expectation of life or on their risk of developing cancer or other fatal diseases. The greater relative risks of leukaemia and of multiple myeloma that were observed previously in the test participants compared with the controls were succeeded by lower relative risks; the initial findings are likely to be due to the chance occurrence of low rates in the control group. The possibility that test participants experienced a small excess risk of leukaemia in the first 25 years after participation cannot be ruled out; but it is difficult to attribute it to any known cause as the risk was not concentrated in those known to have been exposed to radiation, those involved in any particular operation, or those employed in any particular type of job. The other significant differences that we observed previously between the morbidity and the mortality of the participants and the controls, including a deficiency of smoking related diseases and two other types of cancer, disappeared in the extended follow up. Other differences were found in their place, as was to be expected when many diseases were studied. All seem likely to have been chance findings.

We thank the following organisations and people for help in preparing this report: the staff of the Ministry of Defence and the Atomic Weapons Establishment who assisted in the collection of the data; the United States Defense Nuclear Agency, which provided information on United Kingdom participants in the Dominic tests; the organisations that provided follow up information, including the NHS central registers, the Contributions Agency of the Department of Social Security, the health departments in Belfast, Dublin, Guernsey, Jersey, and the Isle of Man, the Ministry of Defence Medical Statistics Department, and staff of the Environmental Monitoring Unit of the Medical Research Council; all who provided lists of independent respondents; Professor Sir David Weatherall who helped review the leukaemia diagnoses; and other national Radiological Protection Board and Imperial Cancer Research Fund staff, including Lindsey Cutler, Barbara MacGibbon, Colin Muirhead, Tracy Silk, Doris Smout, Julia Thomas, and Mark Webb.

1 Darby SC, Kendall GM, Fell TP, O'Hagan JA, Muirhead CR, Ennis JR, et al. A summary of mortality and incidence of cancer in men from the United Kingdom who participated in the United Kingdom's atmospheric nuclear weapon tests and experimental programmes. BMF 1988;296:332-8.

2 Darby SC, Kendall GM, Fell TP, O'Hagan JA, Muiirhead CR, Ennis JR, et al. Morality and incidence of cancer in UK participants in UK atmospheric nuclear weapons tests and experimental programmes. London: HMSO, 1988. (NRPB report R214.)

3 Darby SC, Kendall GM, Fell TP, Doll R, Goodill AA, Conquest AJ, et al. Mortality and cancer incidence 1952-1990 in UK participants in the UK atmospheric nuclear weapon tests and experimental programmes. London: HMSO (in press).

4 World Health Organisation. Manual of the international statistical classification of diseases, injuries and causes of death. 9th revision. Geneva: World Health diseases, injuries and

5 United Nations Scientific Committee on the Effects of Atomic Radiation (UNSCEAR). Sources, effects and risks of ionizing radiation. New York: United Nations, 1988

6 Pearce N, Prior I, Methuen D, Culling C, Marshall S, Auld J, et al. Follow up of New Zealand partipants in British atmospheric nuclear weapon tests in the Pacific. BMF 1990;300:1161-6.

7 International Commission on Radiological Protection. 1990 recommendations of the International Commission on Radiological Protection. Oxford: Pergamon, 1990. (ICRP publication 60.)

8 National Academy of Sciences. Health effects of exposure to low levels of ionizing radiation (BEIR V). Washington, DC: National Academy Press, 1990.

9 National Radiological Protection Board. Estimates of late radiation risks to the UK population. Documents of the NRPB 1993;4:15-157.

(Accepted 25 November 1993)

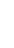
.

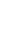

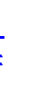

